\title{
ChemComm
}

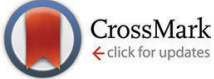

Cite this: Chem. Commun., 2015, 51,6828

Received 21st February 2015, Accepted 11th March 2015

DOI: $10.1039 / \mathrm{c5cc01568e}$

www.rsc.org/chemcomm

\section{Formation of a nanometer-thick water layer at high humidity on a dynamic crystalline material composed of multi-interactive molecules $\dagger$}

\author{
Yumi Yakiyama, $\ddagger^{\mathrm{a}}$ Gil Ryeong Lee, $\ddagger^{\mathrm{a}}$ Sung Yeon Kim, ${ }^{\mathrm{a}}$ Yoshitaka Matsushita, \\ Yasushi Morita, ${ }^{c}$ Moon Jeong Park ${ }^{\text {ad }}$ and Masaki Kawano*a
}

\begin{abstract}
Crystalline powders self-assembled from interactive discrete molecules reversibly transformed from a porous structure to a 2D one with a nanometer-thick $\mathrm{H}_{2} \mathrm{O}$ layer by hydration/dehydration. Multi-point weak intermolecular interactions contributed to maintenance of each phase. This structure transformation induced a humidity-dependent ion conductivity change from insulator to $3.4 \times 10^{-3} \mathrm{~S} \mathrm{~cm}^{-1}$.
\end{abstract}

Intermolecular interactions participate in emerging functions in functional materials ${ }^{1}$ and biological systems. ${ }^{2}$ Especially, multiinteractive interactions contribute to stabilizing key meta-stable intermediates in biological processes, because the multiple interactions can deepen the local minimum potential well to trap kinetic states. ${ }^{3}$ Therefore, we aimed to implement multi-interactivity into a ligand to achieve kinetically self-assembled networks. ${ }^{4}$ We designed a multi-interactive ligand, tri(4-pyridyl)hexaazaphenalene anion (TPHAP ${ }^{-}$), and succeeded in trapping meta-stable coordination networks. ${ }^{5}$ In the process, we unexpectedly prepared crystalline self-assembled materials composed of $\mathrm{K}^{+} \mathrm{TPHAP}^{-}$under highly hydrated conditions. Here we report a 1.2 nm-thick $\mathrm{H}_{2} \mathrm{O}$ layer formed of discrete molecules, and the dynamic structure change revealed by X-ray powder diffraction (XRPD) analysis. ${ }^{6}$ The ion conductivity $\sigma$ of the hydrated material changed from insulator to $3.4 \times 10^{-3} \mathrm{~S} \mathrm{~cm}^{-1}$ depending on the amount of intercalated $\mathrm{H}_{2} \mathrm{O}$.

\footnotetext{
${ }^{a}$ The Division of Advanced Materials Science, Pohang University of Science and Technology (POSTECH), Cheongam-ro 77, Namgu, Pohang 790-784, Korea. E-mail: mkawano@postech.ac.kr; Fax: +82 54279 8736; Tel: +82 542798740

${ }^{b}$ Research Network and Facility Services Division, National Institute for Materials Science (NIMS), Sengen 1-2-1, Tsukuba, Ibaraki 305-0047, Japan

${ }^{c}$ Department of Applied Chemistry, Faculty of Engineering, Aichi Institute of

Technology, Yachigusa 1247, Yakusa, Toyota 470-0392, Japan

${ }^{d}$ Department of Chemistry, Pohang University of Science and Technology

(POSTECH), Cheongam-ro 77, Namgu, Pohang 790-784, Korea

$\dagger$ Electronic supplementary information (ESI) available: Details of the experimental procedures, syntheses of powder crystals, water adsorption experiments, Pulsed-Field-Gradient ${ }^{1} \mathrm{H}$-NMR experiments, IR data and ion conductivity data. CCDC 952977 and 1031002-1031004. For ESI and crystallographic data in CIF or other electronic format see DOI: 10.1039/c5cc01568e

\$ Y.Y. and G.L. share the first authorship.
}

The TPHAP anion has a $D_{3 \mathrm{~h}}$ symmetrical aromatic plane ${ }^{7}$ (Scheme 1) that can form $\pi-\pi$ stacking interaction, and nine nitrogen atoms that can form hydrogen bonds, coordination bonds, or both. ${ }^{5}$ Such multi-interactivity of TPHAP enabled the selective trapping of a kinetic network followed by surfacemediated dynamic structure transformation. ${ }^{5 a}$ We also prepared various coordination networks composed of $\mathrm{Zn}^{2+}$ ions and TPHAP anions from the same crystallization set up by changing only solvents or additives because of the multi-interactivity of TPHAP. ${ }^{5 b, c}$ The interactive nature of TPHAP was also observed in a 1D-channel structure of a $\mathrm{K}^{+} \mathrm{TPHAP}^{-}$single crystal 1 . In the crystal, $\mathrm{H}_{2} \mathrm{O}$ molecules were encapsulated by $\mathrm{OH} \cdots \mathrm{N}$ hydrogen bonds with the $\mathrm{N}$ atoms on the TPHAP ${ }^{-}$skeleton (Fig. S1, ESI $\dagger$ ). Indeed, the single crystal of $\mathrm{K}^{+} \mathrm{TPHAP}^{-}$is highly hygroscopic: $1 \mathrm{~g}$ of powder of $\mathrm{K}^{+} \mathrm{TPHAP}^{-}$adsorbs $>70 \mathrm{~mL}$ of $\mathrm{H}_{2} \mathrm{O}$ (at $25^{\circ} \mathrm{C}, 30 \% \mathrm{RH}$ ) while the potassium salt of the $t$-butyl group substituted hexaazaphenalene (HAP) anion does not

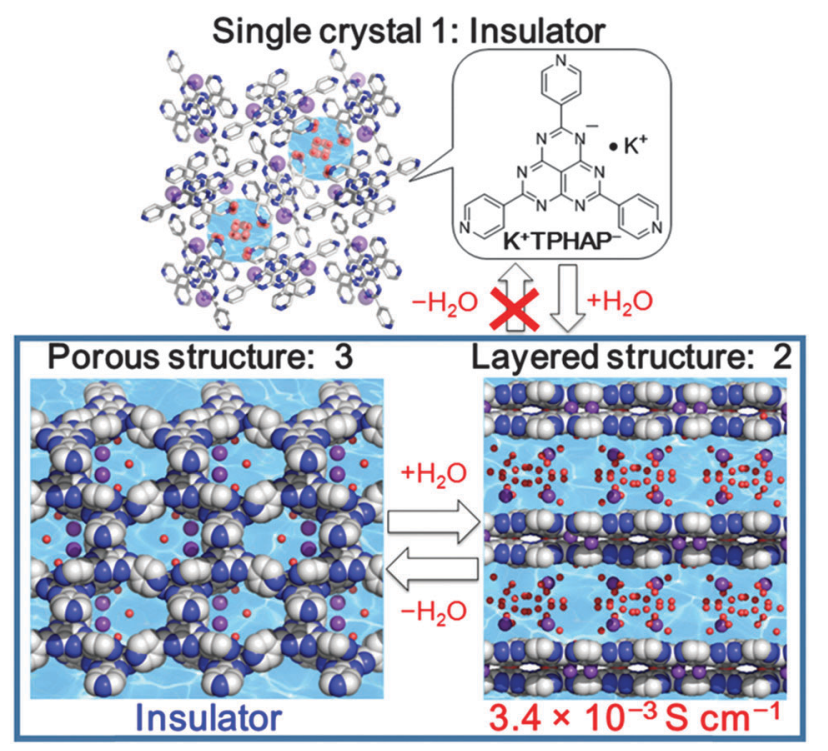

Scheme 1 Schematic model of structure transformation of $\mathrm{K}^{+} \mathrm{TPHAP}$ depending on the humidity. 
show any hygroscopic nature. ${ }^{7 b} \mathrm{~K}^{+} \mathrm{TPHAP}^{-}$powder retained its crystallinity after hydration.

Therefore, we measured the XRPD pattern of fully-hydrated powder 2 which was prepared by hydration of $\mathrm{K}^{+} \mathrm{TPHAP}^{-}$single crystals 1 at $95 \% \mathrm{RH}$ and $25{ }^{\circ} \mathrm{C}$ for 1 day (Fig. 1). The XRPD pattern of 2 showed a drastic and irreversible change from initial $\mathrm{K}^{+} \mathrm{TPHAP}^{-}$single crystalline powder 1 while maintaining a surprisingly high crystallinity. We also identified how the structure changed during drying. We gradually dried fullyhydrated powder 2 by keeping it at $20 \% \mathrm{RH}$ and $20{ }^{\circ} \mathrm{C}$ for $20 \mathrm{~s}$, then quickly measured its XRPD pattern in an airtight cell to avoid further drying during the measurement. This quick drying operation was repeated three times. After the first $20 \mathrm{~s}$, the XRPD pattern was almost intact; the next $20 \mathrm{~s}$ of drying induced drastic changes in the XRPD pattern, and a further $20 \mathrm{~s}$ of drying (total $1 \mathrm{~min}$ ) produced a new phase close to the final state, i.e., 1 day dried powder 3 (Fig. S2, ESI $\dagger$ ). Notably, the sharp powder pattern of 2 was recovered by rehydration of 3. This hydration/dehydration process between 2 and 3 was reversible.

To reveal the reversible structure transformation observed during the hydration/dehydration process, we performed XRPD structure analyses of fully-hydrated powder 2, 1 min dried powder, and 1 day dried powder 3 . The structures were determined by the simulated annealing method in $\mathrm{DASH},{ }^{8}$ followed by Rietveld refinement using RIETAN-FP ${ }^{9}$ to refine the position of each atom with soft bond-angle restraints for a TPHAP group. As a result, we revealed that $1.2 \mathrm{~nm} \mathrm{H}_{2} \mathrm{O}$ layers form in the fully-hydrated 2 (Scheme 1) and that $1 \mathrm{D}_{2} \mathrm{O}$ channels form in 3 by dehydration. Powder structure analysis of 1 min dried powder revealed a severely disordered structure which was an intermediate state before reaching the state of 1 day dried 3 (Fig. S2, ESI $\dagger$ ). It should be noted that although the powder patterns of the 1 min dried powder and 3 look very similar,

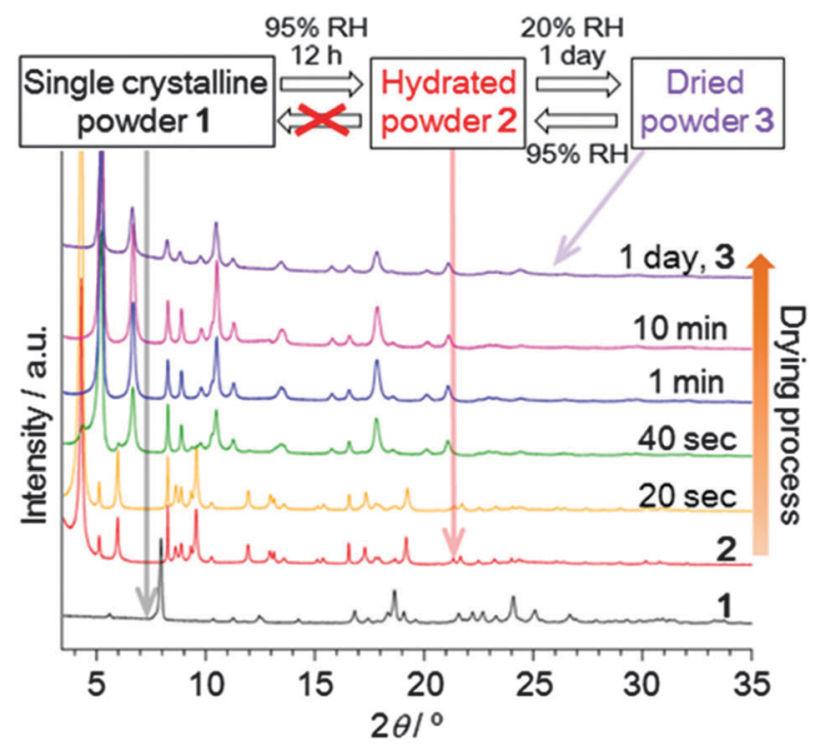

Fig. 1 Synchrotron XRPD pattern changes depending on the amount of water in 1.

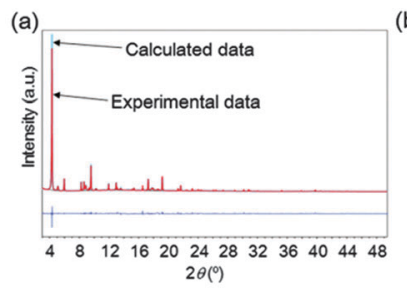

(b)
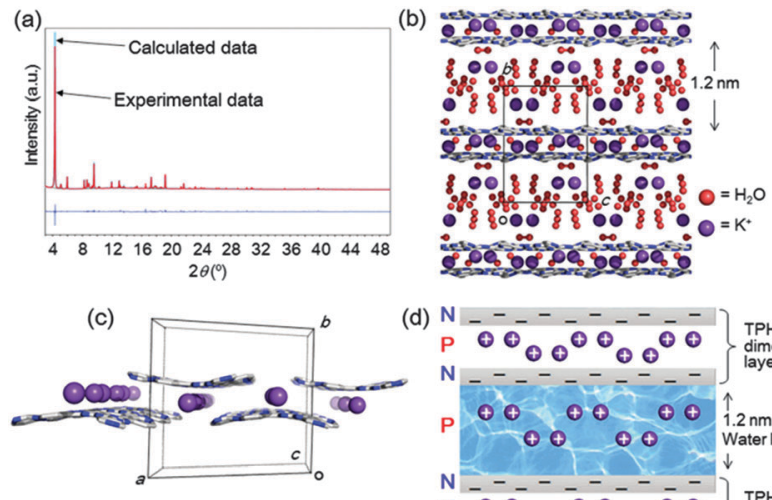

(d) $\left.\mathrm{N}-{ }^{-}-{ }^{-}-{ }^{-}-\overline{-}\right)$ TPHAP

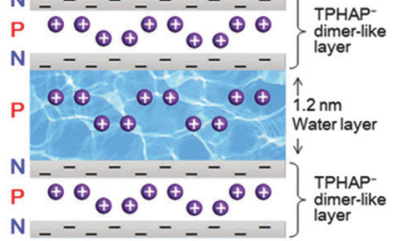

Fig. 2 XRPD analysis of fully-hydrated powder 2. (a) Experimental (red), calculated (pale blue), and difference (blue) diffraction patterns of the best matching model obtained by the final Rietveld refinement of 2 . (b) The best matching model having a 2D layered structure. Synchrotron X-ray radiation $\lambda=1.4639 \AA$. Cell parameter: $a=24.131(5) \AA, b=19.458(2) \AA$, $c=16.672(4) \AA, \beta=122.52(2)^{\circ}$. (c) $2 \mathrm{D}$-sheet composed of $\mathrm{K}^{+} \mathrm{TPHAP}^{-}$dimerlike layers. (d) Schematic model of a charged stacking layer structure. $\mathrm{P}$ : "positively charged layer"; and $\mathrm{N}$ : "negatively charged layer". Color code: C, gray; $\mathrm{N}$, blue; $\mathrm{K}$, purple; $\mathrm{O}$ of $\mathrm{H}_{2} \mathrm{O}$, red.

their unit cells are very different $(1 \mathrm{~min}$ dried powder: $a=$ 20.656(6) ̊, $b=15.978(4) \AA, c=16.80(1) \AA, \beta=100.68(3)^{\circ}, V=$ 5449(4) $\AA^{3}, P 2 / a$; 3: $a=20.90(1) \AA, b=15.93(1) \AA$, $c=9.711(5) \AA$, $\left.\beta=104.65(3)^{\circ}, V=3128(3) \AA^{3}, P 2 / a\right)$.

The powder analysis of 2 revealed four equally possible models that have monoclinic $P 2 / n$ systems that show good agreement between the calculated and experimental XRPD patterns in the final Rietveld refinement (Fig. S3, ESI $\dagger$ ). Among them, one (Fig. 2b) showed the best agreement with the experimental data (Fig. 2a and b). Although the precise determination of disordered $\mathrm{H}_{2} \mathrm{O}$ and $\mathrm{K}^{+}$positions was technically difficult, every refinement result showed flat 2D-sheets composed of $\mathrm{K}^{+} \mathrm{TPHAP}^{-}$dimer-like layers (Fig. 2c) forming $1.2 \mathrm{~nm}$-thick $\mathrm{H}_{2} \mathrm{O}$ layers. These dimer-like layers are stabilized by the intermolecular interactions between the $\mathrm{N}$ atoms of the central HAP skeleton and the disordered $\mathrm{K}^{+}$ions. These interactions are strong enough to be detected by CSI-MS. ${ }^{5 b}$ Some pyridine groups of TPHAP $^{-}$are close to each other, but the short contact can be explained by severe disorder. The amount of $\mathrm{H}_{2} \mathrm{O}$ calculated from XRPD analysis is $31 \mathrm{H}_{2} \mathrm{O}$ molecules per $\mathrm{K}^{+}$TPHAP $^{-}$unit, which is close to the maximum value obtained by direct weight measurement $\left(12-28 \mathrm{H}_{2} \mathrm{O}\right.$ molecules per $\mathrm{K}^{+}$TPHAP $^{-}$unit, Table S1, ESI $\dagger$ ). Notably, other disordered $\mathrm{K}^{+}$ ions were dispersed in the $1.2 \mathrm{~nm}$ water layer. Therefore, stabilization of this $\mathrm{H}_{2} \mathrm{O}$ layer is probably due to a large number of $\mathrm{H}$-bonding interactions between $\mathrm{H}_{2} \mathrm{O}$ molecules and TPHAP skeletons at the boundary and $\mathrm{K}^{+}$ions on the inner part of the $\mathrm{H}_{2} \mathrm{O}$ layer. In addition, the whole structure is constructed as alternating stacks of positively-charged large $\mathrm{H}_{2} \mathrm{O}$ layers and TPHAP $^{-}$dimer-like layers, which are composed of a negativelycharged TPHAP sheet and a positively-charged $\mathrm{K}^{+}$layer (Fig. 2d). This electrically neutral arrangement contributes to stabilization of the 2D layered stacking structure. 
Pulsed-Field-Gradient ${ }^{1} \mathrm{H}-\mathrm{NMR}$ measurement of 2 strongly supported the hypothesized formation of an $\mathrm{H}_{2} \mathrm{O}$ layer with a liquid-like state (Fig. S4, ESI $\dagger$ ). Solid state ${ }^{1} \mathrm{H}$-NMR measurement of 1 (as control) and 2 revealed only one peak corresponding to internal $\mathrm{H}_{2} \mathrm{O}$ at $\delta=5.1$ and $4.4 \mathrm{ppm}$, respectively. The peak corresponding to $\mathbf{1}$ was small and broad due to a much smaller amount of $\mathrm{H}_{2} \mathrm{O}$ in $\mathbf{1}$ than in 2. Furthermore, the large number of hydrogen bonds between $\mathrm{H}_{2} \mathrm{O}$ molecules and the TPHAP $^{-}$skeleton in 1 reduced the mobility of $\mathrm{H}_{2} \mathrm{O} .{ }^{10}$ In contrast, compared to $1, \mathrm{H}_{2} \mathrm{O}$ in fully-hydrated powder 2 could move more freely to give a sharper and larger signal. The diffusion coefficient $D_{\mathrm{H}_{2} \mathrm{O}}$ of water in 2 was obtained from the plot of spin-echo intensity $I / I_{0}=\exp \left[-D \gamma^{2} g^{2} \delta^{2}(\Delta-\delta / 3)\right]$ against the gradient strength $g,{ }^{11}$ where $I$ and $I_{0}$ are the signal intensities with each $g$ and without $g$, respectively, and $\gamma$ is the gyromagnetic ratio. Applied gradient strengths reached $800 \mathrm{G} \mathrm{cm}^{-1}$ while gradient $\delta$ and gradient delay $\Delta$ time values were $0.5 \mathrm{~ms}$ and $3.55 \mathrm{~ms}$, respectively. The obtained $D_{\mathrm{H}_{2} \mathrm{O}}$ value was $1.0 \times 10^{-9} \mathrm{~m}^{2} \mathrm{~s}^{-1}$, which is close to the self-diffusion coefficient of pure $\mathrm{H}_{2} \mathrm{O}$ at $\mathrm{rt}$ (ca. $\left.2 \times 10^{-9} \mathrm{~m}^{2} \mathrm{~s}^{-1}\right) .{ }^{12}$ This quite high $D_{\mathrm{H}_{2} \mathrm{O}}$ value indicates that the diffusion speed of $\mathrm{H}_{2} \mathrm{O}$ molecules in 2 is similar to that in bulk $\mathrm{H}_{2} \mathrm{O}$.

The structural effect of dehydration on the 2D layered structure was also revealed by the XRPD analysis of 1 day dried powder 3 which showed the formation of a porous structure having a monoclinic $P 2 / a$ system with excellent agreement between the calculated and experimental XRPD patterns in the final Rietveld refinement (Fig. 3). In the crystal structure, the ordered TPHAP $^{-}$s also maintain dimer-like structures connected by $\mathrm{K}^{+}$ions and interact with each other by $\pi-\pi$ stacking
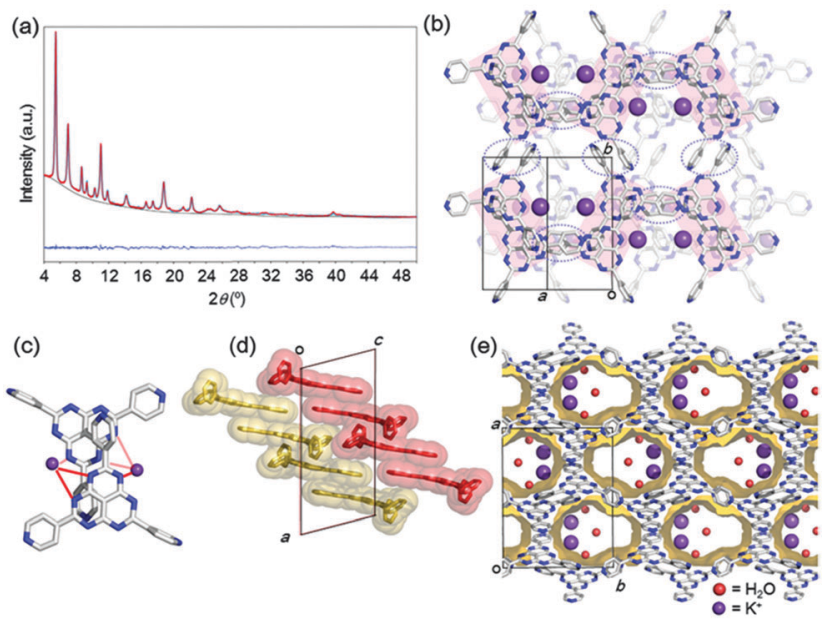

Fig. 3 XRPD analysis of 1 day dried powder 3. (a) Experimental (red), calculated (pale blue), and difference (blue) diffraction patterns after the Rietveld refinement. X-ray radiation $\lambda=1.5406 \AA$. Cell parameter: $a=$ 20.90(1) $\AA, b=15.93(1) \AA, c=9.711(5) \AA, \beta=100.65(3)^{\circ}$. (b) $2 \mathrm{D}$ layered structure formed by $\pi-\pi$ stacking of dimer-like TPHAP $^{-} s$ (pale red rectangles). Pale blue dotted circles: stacking position. (c) Dimer-like structure composed of two $\mathrm{K}^{+} \mathrm{TPHAP}^{-}$s. Red lines: ionic bond between the $\mathrm{N}$ atom and $\mathrm{K}^{+}$. (d) Stacking structure of 2D layered structures. Red and yellow components represent layers. (e) 1D channel structure in 3. Color code: $\mathrm{C}$, gray; $\mathrm{N}$, blue; $\mathrm{K}$, purple; $\mathrm{O}$ of $\mathrm{H}_{2} \mathrm{O}$, red. to form a 2D layer (Fig. 3b and c). The 2D layers stack with the shortest distance (Fig. 3d), followed by formation of $1 \mathrm{D}$ channels along the $c$ axis with a size of $c a .12 \AA \times 16 \AA$ (Fig. 3e). In the XRPD analysis, we could model only two $\mathrm{H}_{2} \mathrm{O}$ molecules per $\mathrm{K}^{+}$TPHAP $^{-}$unit in the channel, although elemental analysis indicated five $\mathrm{H}_{2} \mathrm{O}$ molecules per $\mathrm{K}^{+}$TPHAP $^{-}$unit. Notably, the $1 \mathrm{D}$ channel is surrounded by $\mathrm{N}$ atoms on a HAP skeleton as observed in a $\mathrm{K}^{+}$TPHAP $^{-}$single crystal 1 in which $\mathrm{K}^{+}$ions and $\mathrm{H}_{2} \mathrm{O}$ molecules are less mobile than in 2 . Therefore, the significant mobility decrease of $\mathrm{K}^{+}$ions and $\mathrm{H}_{2} \mathrm{O}$ was expected as a result of the structural transformation from a $2 \mathrm{D}$-layered structure to a $1 \mathrm{D}$-porous structure. This reduction is also suggested by humidity-dependent IR spectra (Fig. S5, ESI $\dagger$ ). As the amount of absorbed $\mathrm{H}_{2} \mathrm{O}$ decreased, the peaks at $\sim 1500-1600 \mathrm{~cm}^{-1}$ attributable to the $\mathrm{C}=\mathrm{N}$ and $\mathrm{C}=\mathrm{C}$ stretching modes of pyridine and the central skeleton of TPHAP ${ }^{-}$ showed clear red shifts: $\sim 10 \mathrm{~cm}^{-1}$ from the fully-hydrated powder 2 to single crystal $1 ; 4-5 \mathrm{~cm}^{-1}$ from 2 to 1 day dried powder 3 . These peak shifts can be explained by enhancement of Coulombic interaction between $\mathrm{K}^{+}$and the anionic HAP skeleton and by hydrogen bond formation between TPHAP $^{-}$ and $\mathrm{H}_{2} \mathrm{O} .{ }^{13}$ This discussion indicates that this dynamic structure transformation can make a significant contribution to the ion conductivity of $\mathrm{K}^{+}$TPHAP $^{-}$because the conductivity value has a strong relationship with charge carrier mobility. ${ }^{14}$ Therefore, we finally performed humidity-dependent ion conductivity measurement and tried to interpret the relationship between the structure and the conduction property.

The ion conductivity of $\mathrm{K}^{+}$TPHAP $^{-}$single crystalline powder 1 was significantly correlated with the outer humidity. We measured the ion conductivity of a compressed pellet of $\mathbf{1}$ ( $\phi 13 \mathrm{~mm}$, thickness $\sim 0.2 \mathrm{~mm}$ ) by ac impedance spectroscopy under various conditions of humidity and temperature (ESI $\dagger$ ). The conductivity drastically changed from insulator at $20 \% \mathrm{RH}$ to $3.4 \times 10^{-3} \mathrm{~S} \mathrm{~cm}^{-1}$ at $95 \% \mathrm{RH}\left(25^{\circ} \mathrm{C}\right.$, Fig. 4). Although a large amount of $\mathrm{H}_{2} \mathrm{O}$ adsorption in the highly conductive state was observed (Table S1, ESI $\dagger$ ), the pellet of 1 remained soft and solid after conductivity measurement (Fig. S6, ESI $\dagger$ ). We unambiguously confirmed that the highly-conductive state corresponds to 2 having a 2D layered structure by XRPD measurement of the pellet sample (Fig. S7, ESI $\dagger$ ). In contrast, drying of the fully-hydrated pellet even for several seconds reduced its conductivity value significantly. This phenomenon reminded us of the quick structural transformation of 2 to the dried state 3 . We confirmed by XRPD

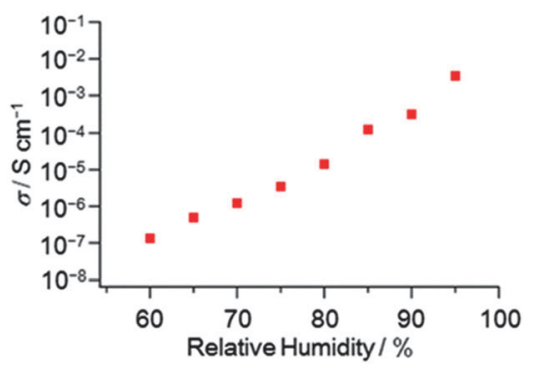

Fig. 4 Humidity dependence of the ionic conductivity $\sigma$ of 1 at $25^{\circ} \mathrm{C}$. 
analysis that the dried pellet corresponds to 3 which possesses a porous structure (Fig. S6, ESI $\dagger$ ). Because the system contains no mobile proton $\left(\mathrm{H}^{+}\right),{ }^{15}$ the main charge carrier is very likely $\mathrm{K}^{+}$. In fact, the $\mathrm{K}^{+}$-exchanged proton conducting polymer shows $\sigma=\sim 3.0 \times 10^{-2} \mathrm{~S} \mathrm{~cm}^{-1}$ (fully-hydrated at $25^{\circ} \mathrm{C}$ ) which gives the diffusion coefficient of $\mathrm{K}^{+}$rather than of $\mathrm{H}^{+}{ }^{16}$ These facts indicate that the main carrier that contributes to ion conductivity is a metal cation. From the above discussion, this drastic conductivity change can be explained based on the changes of the structure and the amount of water in the system. In the hydrated state of $2, \mathrm{~K}^{+}$can readily diffuse by weak van der Waals interaction with $\mathrm{H}_{2} \mathrm{O}$ within the $1.2 \mathrm{~nm} \mathrm{H}_{2} \mathrm{O}$ layer because the diffusion rate of $\mathrm{H}_{2} \mathrm{O}$ is almost the same as that of bulk $\mathrm{H}_{2} \mathrm{O}$. This wide $\mathrm{H}_{2} \mathrm{O}$ layer also contributes to the smooth migration of $\mathrm{K}^{+}$by keeping away $\mathrm{K}^{+}$from the surface of the TPHAP ${ }^{-}$layer. This effective $\mathrm{K}^{+}$migration supported by the fast diffusion of bulk-like $\mathrm{H}_{2} \mathrm{O}$ realized the high conductivity under humid conditions. Oppositely, the structure transformation of 2 to porous 3 by drying causes a significant decrease in the mobility of $\mathrm{K}^{+}$ions and $\mathrm{H}_{2} \mathrm{O}$; the large amount of $\mathrm{H}_{2} \mathrm{O}$ removal involving this structure transformation increases the contribution of strong $\mathrm{H}$-bonds between $\mathrm{N}$ atoms on the TPHAP skeleton and $\mathrm{K}^{+}$or $\mathrm{H}_{2} \mathrm{O}$ compared to that in 2 . Therefore, the significant conductivity decrease by dehydration is attributed to the decreased mobility of $\mathrm{K}^{+}$and $\mathrm{H}_{2} \mathrm{O}$ due to structural transformation from the 2D-layered structure to the interactive $1 \mathrm{D}$-porous structure.

We revealed formation of a nanometer-thick $\mathrm{H}_{2} \mathrm{O}$ layer on a multi-interactive ligand, $\mathrm{K}^{+} \mathrm{TPHAP}^{-}$, by XRPD analysis. We also found reversible shrinkage/expansion of the hydrated powder by dehydration/hydration. This structural transformation corresponded to a drastic change of ion conductivity from insulator to $3.4 \times 10^{-3} \mathrm{~S} \mathrm{~cm}^{-1}$. Our material may provide better understanding of the correlation between the structure and the physical properties of $\mathrm{H}_{2} \mathrm{O}$ - or humidity-triggered functional materials.

This work was supported by the National Research Foundation of Korea (NRF) grant funded by the Korea government (MSIP) (No. 2014R1A2A1A11049978) and Basic Science Research Institute Grant from POSTECH. This work has been approved by the Photon Factory Advisory Committee (Proposal No. 2014G008, beamline NW2A). X-ray powder diffraction studies with synchrotron radiation were performed at the Pohang Accelerator Laboratory (Beamline 2D and 9B) and at the BL15XU, SPring-8 with the approval of the National Institute for Materials Science (NIMS) (Proposal No. 2009A4800).

\section{Notes and references}

1 Supramolecular Chemistry, ed. J. W. Steed and J. L. Atwood, Wiley, Chichester, UK, 2nd edn, 2009.

2 (a) D. Stock, A. G. W. Leslie and J. E. Walker, Science, 1999, 286, 1700-1705; (b) N. Ban, P. Nissen, J. Hansen, P. B. Moore and T. A. Steitz, Science, 2000, 289, 905-920; (c) N. H. Joh, A. Min, S. Faham, J. P. Whitelegge, D. Yang, V. L. Woods, Jr. and J. U. Bowie, Nature, 2008, 453, 1266-1270; (d) D. M. Rosenbaum, S. G. F. Rasmussen and B. K. Kobilka, Nature, 2009, 459, 356-363.

3 (a) M. M. Gromiha and S. Selvaraj, Prog. Biophys. Mol. Biol., 2004, 86, 235-277; (b) M. Chaplin, Nat. Rev. Mol. Cell Biol., 2006, 7, 861-866.

4 (a) M. Kawano, T. Haneda, D. Hashizume, F. Izumi and M. Fujita, Angew. Chem., Int. Ed., 2008, 47, 1269-1271; (b) J. Martí-Rujas, Y. Matsushita, F. Izumi, M. Fujita and M. Kawano, Chem. Commun., 2010, 46, 6515-6517; (c) H. Kitagawa, H. Ohtsu and M. Kawano, Angew. Chem., Int. Ed., 2013, 52, 12395-12399.

5 (a) Y. Yakiyama, A. Ueda, Y. Morita and M. Kawano, Chem. Commun., 2012, 48, 10651-10653; (b) T. Kojima, T. Yamada, Y. Yakiyama, E. Ishikawa, Y. Morita, M. Ebihara and M. Kawano, CrystEngComm, 2014, 16, 6335-6344.

6 (a) M. Takata, B. Umeda, E. Nishibori, M. Sakata, Y. Saito, M. Ohno and H. Shinohara, Nature, 1995, 377, 46-49; (b) S. Pagola, P. W. Stephens, D. S. Bohle, A. D. Kosar and S. K. Madsen, Nature, 2000, 404, 307-310; (c) IUCr Monographs on Crystallography 13, ed. W. I. F. David, D. Shankland, L. B. McCusker and C. Baerlocher, Oxford University Press, Oxford, UK, 2002; (d) K. D. M. Harris and E. Y. Cheung, Chem. Soc. Rev., 2004, 33, 526-538; (e) J. Martí-Rujas and M. Kawano, Acc. Chem. Res., 2013, 46, 493-505.

7 (a) S. Suzuki, Y. Morita, K. Fukui, K. Sato, D. Shiomi, T. Takui and K. Nakasuji, Inorg. Chem., 2005, 44, 8197-8199; (b) S. Suzuki, K. Fukui, A. Fuyuhiro, K. Sato, T. Takui, K. Nakasuji and Y. Morita, Org. Lett., 2010, 12, 5036-5039.

8 W. I. F. David, K. Shankland and N. Shankland, Chem. Commun., 1998, 931-932.

9 F. Izumi and K. Momma, Solid State Phenom., 2007, 130, 15-20.

10 S. Hietala, S. L. Maunu, F. Sundholm, T. Lehtinen and G. Sundholm, J. Polym. Sci., Part B: Polym. Phys., 1999, 37, 2893-2900.

11 (a) J. E. Tanner, J. Chem. Phys., 1970, 52, 2523-2526; (b) T. A. Zawodzinski, Jr., M. Neeman, L. O. Sillerud and S. Gottesfeld, J. Phys. Chem., 1991, 95, 6040-6044.

12 M. Holz, S. R. Heil and A. Sacco, Phys. Chem. Chem. Phys., 2000, 2, 4740-4742.

13 M. Vilkman, A. Lankinen, N. Volk, P. Kostamo and O. Ikkala, Polymer, 2010, 51, 4095-4102.

14 Modern Electrochemistry vol 1: Ionics, ed. J. O. Bockris and A. K. N. Reddy, Springer, 2nd edn, 1998.

15 Examples of organic molecule-based water-mediated proton conductors which keep rigid structures in humid condition see; (a) M. Sadakiyo, T. Yamada and H. Kitagawa, J. Am. Chem. Soc., 2009, 131, 9906-9907; (b) L. Jiménez-García, A. Kaltbeitzel, W. Pisula, J. S. Gutmann, M. Klapper and K. Müllen, Angew. Chem., Int. Ed., 2009, 48, 9951-9953; (c) M. Yoon, K. Suh, H. Kim, Y. Kim, N. Selvapalam and K. Kim, Angew. Chem., Int. Ed., 2011, 50, 7870-7873; (d) J. M. Taylor, K. W. Dawson and G. K. H. Shimizu, J. Am. Chem. Soc., 2013, 135, 1193-1196.

16 T. Okada, H. Satou, M. Okuno and M. Yuasa, J. Phys. Chem. B, 2002, 106, 1267-1273. 